\title{
Accumulation of the solvent vehicle sulphobutylether beta cyclodextrin sodium in critically ill patients treated with intravenous voriconazole under renal replacement therapy Marc A von Mach*1, Jürgen Burhenne ${ }^{2}$ and Ludwig S Weilemann ${ }^{1}$
}

Address: ${ }^{1}$ Division of Intensive Care Medicine and Clinical Toxicology, II. Medical Department, University of Mainz, Langenbeckstr. 1, 55131 Mainz, Germany and 2Department of Internal Medicine VI, Clinical Pharmacology and Pharmacoepidemiology, University of Heidelberg, Im Neuenheimer Feld 410, 69120 Heidelberg, Germany

Email: Marc A von Mach* - marcm@giftinfo.uni-mainz.de; Jürgen Burhenne - juergen.burhenne@med.uni-heidelberg.de; Ludwig S Weilemann - sacha@giftinfo.uni-mainz.de

* Corresponding author

Published: 18 September 2006

BMC Clinical Pharmacology 2006, 6:6 doi:10.1 186/1472-6904-6-6

This article is available from: http://www.biomedcentral.com/1472-6904/6/6

(C) 2006 von Mach et al; licensee BioMed Central Ltd.

This is an Open Access article distributed under the terms of the Creative Commons Attribution License (http://creativecommons.org/licenses/by/2.0), which permits unrestricted use, distribution, and reproduction in any medium, provided the original work is properly cited.

\begin{abstract}
Background: Voriconazole was introduced for the treatment of life-threatening fungal infections. The intravenous form includes the solvent vehicle sulphobutylether beta cyclodextrin sodium which shows an impaired clearance under intermittent dialysis therapy. This investigation aimed to determine first clinical data on sulphobutylether beta cyclodextrin sodium blood levels to verify the risk for accumulation.
\end{abstract}

Methods: In four patients suffering from renal insufficiency and intermittent dialysis therapy who needed a treatment with intravenous voriconazole as a reserve antifungal at the intensive care unit of the Mainz University Hospital the trough levels of voriconazole and sulphobutylether beta cyclodextrin sodium were measured.

Results: A 75-year-old woman showed a maximal sulphobutylether beta cyclodextrin sodium plasma level of $145 \mu \mathrm{g} / \mathrm{ml}$ in the initial phase. After a few days renal function recovered and the plasma levels came down to less than $20 \mu \mathrm{g} / \mathrm{ml}$. In contrast to this patient with a recovery of renal function the remaining three patients showed renal failure during the complete period of intravenous treatment with voriconazole. In these patients an accumulation of sulphobutylether beta cyclodextrin sodium plasma levels was determined with a maximum of $523 \mu \mathrm{g} / \mathrm{ml}$ in a I 8-yearold man, $409 \mu \mathrm{g} / \mathrm{ml}$ in a 57 -year-old man, and $58 \mathrm{l} \mu \mathrm{g} / \mathrm{ml}$ in a 47 -year-old man.

Conclusion: The present data indicate an accumulation of sulphobutylether beta cyclodextrin sodium in patients treated with intravenous voriconazole and dialysis therapy. Fortunately, no toxic effects were observed, although the accumulated dose values were lower but comparable with those used in previous toxicity studies with animals.

\section{Background}

The triazole antifungal, voriconazole, was introduced for the treatment of life-threatening fungal infections. The drug, which is available for both oral and intravenous administration, has broad-spectrum activity against pathogenic yeasts, dimorphic fungi and opportunistic moulds 
$[1,2]$. As voriconazole has limited aqueous solubility, the intravenous form includes the solvent vehicle sulphobutylether beta cyclodextrin sodium as a novel delivery system [3]. In healthy subjects sulphobutylether beta cyclodextrin sodium is rapidly eliminated with a terminal half-life of 1.6 hours. The clearance of sulphobutylether beta cyclodextrin sodium is linearly related to creatinine clearance and accumulation has been described in subjects with moderate to severe renal impairment (serum creatinine levels $>2.5 \mathrm{mg} / \mathrm{dl}$ ) [4]. In patients with an estimated creatinine clearance of 30 to $50 \mathrm{ml} / \mathrm{min}$ the mean Cmax and AUC of sulphobutylether beta cyclodextrin sodium increased by almost $50 \%$ and 4 -fold, respectively, compared to subjects with normal renal function [5]. Additionally, sulphobutylether beta cyclodextrin sodium is known to show an impaired clearance under dialysis therapy of $55 \mathrm{ml} / \mathrm{min}$ determined in volunteers with renal failure undergoing hemodialysis [6]. Clinical data regarding this problem have not been available so far. The manufacturer suggests to balance the possible risk of accumulation of sulphobutylether beta cyclodextrin sodium and the benefit of the antifungal effect [7]. Furthermore, it is recommended to treat patients on dialysis therapy only with the oral form of voriconazole if feasible. However, in critically ill patients with complicated lifethreatening fungal infections a save oral administration of drugs is difficult to accomplish as, for instance, extensive gastric reflux, gastrointestinal bleedings or mucositis are frequent comorbidities. In animal experiments the acute toxicity of sulphobutylether beta cyclodextrin sodium has been observed to be low. The minimal lethal dose was $2000 \mathrm{mg} / \mathrm{kg}$. Target organs for toxic effects in rodents were kidney and liver with obstruction of renal tubules and single cell necrosis in the liver. Both findings were a consequence of massive cytoplasmic vacuolation [4]. In two healthy volunteers peak sulphobutylether beta cyclodextrin sodium levels of 118 and $130 \mu \mathrm{g} / \mathrm{ml}$, respectively, were measured immediately following administration of $1600 \mathrm{mg}$ sulphobutylether beta cyclodextrin sodium as a single 15 minutes intravenous infusion [8]. The present investigation aimed to determine first clinical data on sulphobutylether beta cyclodextrin sodium blood levels to verify the risk for accumulation.

\section{Methods \\ Subjects}

From March 2003 to January 2006 a total number of 29 critically ill patients (17 male, 12 female) needed a treatment with intravenous voriconazole as a reserve antifungal at the 10-bed general intensive care unit of the Mainz University Hospital. 15 patients $(51.7 \%)$ required intermittent dialysis due to acute (14 patients) or chronic (1 patient) renal failure. In four patients suffering from renal insufficiency the trough plasma levels of voriconazole and sulphobutylether beta cyclodextrin sodium were meas- ured. Blood samples were collected in Monovette plastic tubes and immediately centrifuged at $2000 \mathrm{~g}$ at $4{ }^{\circ} \mathrm{C}$. This investigation was approved by the Institutional Review Board (Rheinland-Pfalz, Germany). The board waived the need for informed consent. Additionally, monitoring for possible toxic effects of sulphobutylether beta cyclodextrin sodium regarding level of consciousness, hemodynamic stability, dermal reactions, and liver function tests was performed.

\section{Voriconazole and sulphobutylether beta cyclodextrin sodium measurements}

Voriconazole was determined according to a previously published method [9]. In brief, plasma samples were spiked with internal standard and borate buffer was added. The samples were loaded onto solid phase extraction (SPE) columns, washed with buffer and methanol/ water, and eluted with methanol/acetic acid mixture. After drying, the extracts were reconstituted with mobile HPLC phase and analyzed by HPLC/UV. The limit of quantification was $0.2 \mu \mathrm{g} / \mathrm{ml}$. The precision of determination (coefficient of variation) was $7.2,7.9,3.2$, and $3.7 \%$ at quality control concentrations of $0.2,0.4,3.4$, and $6.9 \mu \mathrm{g} / \mathrm{ml}$, respectively. Sulphobutylether beta cyclodextrin sodium was determined according to a previously published method [8]: Phosphate buffer was added to plasma samples before loading onto SPE columns (Chromabond, cyclohexyl). The loaded SPE columns were washed with buffer and eluted with methanol/water (30/70) mixture. After drying, the extracts were reconstituted in methanol/ water (10/90) and analyzed by HPLC/Fluorescence. The limit of quantification was $4.00 \mu \mathrm{g} / \mathrm{ml}$. The precision of determination (coefficient of variation) was 5.7, 6.7, 7.0, and $6.9 \%$ at quality control concentrations of $4.00,14.9$, 65.2 , and $126 \mu \mathrm{g} / \mathrm{ml}$, respectively. The analytical methods were validated according to FDA validation guidelines and fulfilled the respective quality assurance for accuracy and precision.

\section{Results}

The analysis of the four patients suffering from renal insufficiency for whom plasma levels of voriconazole and sulphobutylether beta cyclodextrin sodium were measured revealed two different courses of renal impairment which required a clear differentiation:

\section{Patients with restoration of renal function}

A 75-year-old woman submitted with acute myeloid leukemia showed a maximal sulphobutylether beta cyclodextrin sodium plasma level of $145 \mu \mathrm{g} / \mathrm{ml}$ in the initial phase of treatment with intravenous voriconazole (Figure 1, Table 1, patient no. 1). After a few days renal function recovered and the plasma levels came down to less than $20 \mu \mathrm{g} / \mathrm{ml}$ after 10 days of treatment with intravenous voriconazole. 
Table I: Voriconazole (VOR) and sulphobutylether beta cyclodextrin sodium (SBECD) plasma levels in patients with intravenous voriconazole therapy and renal failure

\begin{tabular}{|c|c|c|c|c|c|c|}
\hline patient no. & day of VOR therapy & dose of intravenous VOR & dose of SBECD & dialysis information & $\operatorname{VOR}(\mu \mathrm{g} / \mathrm{ml})$ & SBECD $(\mu \mathrm{g} / \mathrm{ml})$ \\
\hline I & 2 & $2 \times 400 \mathrm{mg}$ & $2 \times 6400 \mathrm{mg}$ & before dialysis & 0.9 & 98.3 \\
\hline 1 & 2 & $2 \times 200 \mathrm{mg}$ & $2 \times 3200 \mathrm{mg}$ & after dialysis & 1.1 & 145 \\
\hline I & 3 & $2 \times 200 \mathrm{mg}$ & $2 \times 3200 \mathrm{mg}$ & before dialysis & 0.2 & 93.3 \\
\hline I & 4 & $2 \times 200 \mathrm{mg}$ & $2 \times 3200 \mathrm{mg}$ & after dialysis & $<0.2$ & 121 \\
\hline I & 7 & $2 \times 200 \mathrm{mg}$ & $2 \times 3200 \mathrm{mg}$ & after dialysis & 0.4 & 78.9 \\
\hline I & 8 & $2 \times 200 \mathrm{mg}$ & $2 \times 3200 \mathrm{mg}$ & before dialysis & 0.5 & 86.4 \\
\hline I & 9 & $2 \times 200 \mathrm{mg}$ & $2 \times 3200 \mathrm{mg}$ & before dialysis & 0.4 & 59.6 \\
\hline I & 9 & $2 \times 200 \mathrm{mg}$ & $2 \times 3200 \mathrm{mg}$ & after dialysis & $<0.2$ & 31.4 \\
\hline I & 10 & $2 \times 200 \mathrm{mg}$ & $2 \times 3200 \mathrm{mg}$ & before dialysis & 0.3 & 71.6 \\
\hline I & 12 & $2 \times 200 \mathrm{mg}$ & $2 \times 3200 \mathrm{mg}$ & no dialysis & $<0.2$ & 15.6 \\
\hline I & 13 & $2 \times 200 \mathrm{mg}$ & $2 \times 3200 \mathrm{mg}$ & no dialysis & $<0.2$ & 16.4 \\
\hline I & 16 & $2 \times 200 \mathrm{mg}$ & $2 \times 3200 \mathrm{mg}$ & no dialysis & $<0.2$ & 18.4 \\
\hline 2 & 10 & $2 \times 200 \mathrm{mg}$ & $2 \times 3200 \mathrm{mg}$ & before dialysis & 0.4 & 523 \\
\hline 2 & 11 & $2 \times 200 \mathrm{mg}$ & $2 \times 3200 \mathrm{mg}$ & after dialysis & 0.3 & 400 \\
\hline 2 & 12 & $2 \times 200 \mathrm{mg}$ & $2 \times 3200 \mathrm{mg}$ & no dialysis & 0.3 & 348 \\
\hline 2 & 13 & $2 \times 200 \mathrm{mg}$ & $2 \times 3200 \mathrm{mg}$ & no dialysis & 0.7 & 508 \\
\hline 3 & 4 & $2 \times 400 \mathrm{mg}$ & $2 \times 6400 \mathrm{mg}$ & no dialysis & 3.8 & 110 \\
\hline 3 & 8 & $2 \times 400 \mathrm{mg}$ & $2 \times 6400 \mathrm{mg}$ & before dialysis & 5.1 & 314 \\
\hline 3 & 10 & $2 \times 400 \mathrm{mg}$ & $2 \times 6400 \mathrm{mg}$ & after dialysis & 3.2 & 409 \\
\hline 3 & 11 & $2 \times 400 \mathrm{mg}$ & $2 \times 6400 \mathrm{mg}$ & after dialysis & 2.6 & 200 \\
\hline 4 & 1 & $2 \times 400 \mathrm{mg}$ & $2 \times 6400 \mathrm{mg}$ & before dialysis & 1.4 & 344 \\
\hline 4 & 5 & $2 \times 200 \mathrm{mg}$ & $2 \times 3200 \mathrm{mg}$ & before dialysis & 0.3 & 271 \\
\hline 4 & 7 & $2 \times 200 \mathrm{mg}$ & $2 \times 3200 \mathrm{mg}$ & before dialysis & 0.3 & 451 \\
\hline 4 & 8 & $2 \times 200 \mathrm{mg}$ & $2 \times 3200 \mathrm{mg}$ & after dialysis & 0.3 & 483 \\
\hline 4 & 9 & $2 \times 200 \mathrm{mg}$ & $2 \times 3200 \mathrm{mg}$ & no dialysis & 0.9 & 456 \\
\hline 4 & 12 & $2 \times 200 \mathrm{mg}$ & $2 \times 3200 \mathrm{mg}$ & after dialysis & I.I & 505 \\
\hline 4 & 13 & $2 \times 200 \mathrm{mg}$ & $2 \times 3200 \mathrm{mg}$ & before dialysis & 1.3 & 581 \\
\hline 4 & 13 & $2 \times 200 \mathrm{mg}$ & $2 \times 3200 \mathrm{mg}$ & after dialysis & 0.9 & 563 \\
\hline
\end{tabular}

\section{Patients without restoration of renal function}

In contrast to the patient with a recovery of renal function the remaining three patients showed renal failure during the complete period of intravenous treatment with voriconazole. In these patients an accumulation of sulphobutylether beta cyclodextrin sodium plasma levels was determined with a maximum of $523 \mu \mathrm{g} / \mathrm{ml}$ in a 18 year-old man submitted with myocarditis (Table 1, patient no. 2), $409 \mu \mathrm{g} / \mathrm{ml}$ in a 57 -year-old man submitted with multiple myeloma (Table 1, patient no. 3), and 581 $\mu \mathrm{g} / \mathrm{ml}$ in a 47 -year-old man submitted with intestinal ischemia (Table 1, patient no. 4).

\section{Voriconazole plasma levels}

Besides sulphobutylether beta cyclodextrin sodium voriconazole plasma levels were determined which were most commonly less than $1.5 \mu \mathrm{g} / \mathrm{ml}$ and showed no evidence for accumulation (Table 1). In patient no. 1 the levels were, in part, not detectable. In patient no. 3 all voriconazole measurements were distinctly elevated as compared to the remaining patients which was due to a concomittant hepatic insufficiency.

\section{Technical aspects of dialysis, clinical and biochemical monitoring}

Hemodialysis in the four patients was performed using a low flux AM-BIO 750 cartridge (ASAHI KASEI MEDICAL EUROPE GmbH, Frankfurt, Germany). The average frequency of the dialysis sessions was every 24 to 48 hours, the duration was 4 hours, blood flow 200 to $220 \mathrm{ml} / \mathrm{min}$, and fluid extraction 2 to 3 liters to maintain proper fluid balance. Clinical and biochemical data to assess the toxicity of accumulation of sulphobutylether beta cyclodextrin sodium were determined but in these critically ill patients with complicated disease it was difficult to trace back possible effects. Patient no. 3 was sedated, intubated and mechanically ventilated during the whole course of intravenous voriconazole treatment. Patients no. 2 and 4 were awake but tracheotomized and not fully orientated. Patient no. 1 was extubated but she was somnolent and could not answer questions. None of the patients showed an obvious deterioration of the level of consciousness during the treatment with voriconazole. A more detailed assessment like testing for the frequently described side effect of visual disturbances under intravenous voricona- 
Table 2: Liver function tests in patients with renal failure at start and end of intravenous voriconazole therapy

\begin{tabular}{|c|c|c|c|c|c|c|}
\hline & \multicolumn{2}{|c|}{$\operatorname{ASAT}(\mathrm{IU} / \mathrm{I})^{a}$} & \multicolumn{2}{|c|}{$\gamma$-GT $(\mathrm{IU} / \mathrm{I})^{b}$} & \multicolumn{2}{|c|}{ Total bilirubin $(\mathrm{mg} / \mathrm{dl})^{c}$} \\
\hline & start & end & start & end & start & end \\
\hline patient no. I & 104 & 24 & 119 & 264 & 2.32 & 1.39 \\
\hline patient no. 2 & 100 & 26 & 93 & 71 & 0.83 & 0.32 \\
\hline patient no. 3 & 54 & 25 & 288 & 443 & 4.93 & 7.27 \\
\hline patient no. 4 & 30 & 22 & 238 & 216 & 3.29 & 1.34 \\
\hline
\end{tabular}

${ }^{a}$ norm $<37$ IU/I, bnorm 10-66 IU/L, cnorm 0.1-1.2 mg/dl

zole could not be performed in these patients. Dermal reactions were not observed under intravenous voriconazole treatment. Patients no. 1, 2, and 4 were hemodynamically stable without catecholamines. Patient no. 3 needed treatment with noradrenaline which required adjustment to individual situations like during high fever or during dialysis. Liver function test results at the beginning of intravenous voriconazole treatment compared to the end of treatment showed the hepatic impairment of patient no. 3 (Table 2).

\section{Discussion}

Patients with the need for an intravenous treatment with voriconazole were rare with about 10 patients per year at the 10-bed general intensive care unit. However, when such a treatment was required more than half of the patients were under renal replacement therapy.

\section{Sulphobutylether beta cyclodextrin sodium findings}

The present data indicate an accumulation of sulphobutylether beta cyclodextrin sodium in patients with renal failure and intermittent dialysis therapy given intravenous voriconazole in whom restoration of renal function was not achieved during the treatment course. In contrast, in the patient in whom restoration of renal function was obtained early during the treatment with intravenous voriconazole, accumulation of sulphobutylether beta cyclodextrin sodium was not observed. Fortunately, there was no evidence for toxic effects related to the concentrations of sulphobutylether beta cyclodextrin sodium measured in these patients. Assuming no abnormalities in the volume distribution (the steady-state volume of distribution of sulphobutylether beta cyclodextrin sodium is approximately $0.2 \mathrm{~L} / \mathrm{kg}$, which is similar to extracellular fluid volume in humans) the maximal concentration values of sulphobutylether beta cyclodextrin sodium would be translate back to a total amount of about $100 \mathrm{mg} / \mathrm{kg}$ accumulated sulphobutylether beta cyclodextrin sodium on board. This extrapolated dose value was about 10 -fold lower than the usual doses used in animal models for toxicity assessment. In animal experiments the minimal single lethal dose has been determined to be $2000 \mathrm{mg} / \mathrm{kg}$, while daily doses of $1000 \mathrm{mg} / \mathrm{kg}$ for one month or 600 $\mathrm{mg} / \mathrm{kg}$ for six months did not produce functional renal changes [4]. Assuming a half-life of sulphobutylether beta cyclodextrin sodium in healthy animals of 1.6 hours the single doses of 1000 or $600 \mathrm{mg} / \mathrm{kg}$ would have been eliminated within a few hours (animals receiving $1000 \mathrm{mg} / \mathrm{kg}$ would have less than $100 \mathrm{mg} / \mathrm{kg}$ on board within about 3.5 hours). In contrast, the $100 \mathrm{mg} / \mathrm{kg}$ in our patients with renal failure would represent a continuous baseline level. Therefore, the range of the presently determined sulphobutylether beta cyclodextrin sodium concentrations might well be considered to be toxic from clinical perspective. Nevertheless, for comparisons with animal data a word of caution is suitable regarding the presently investigated patients with renal insufficiency. The sick kidney may be protected from the toxic action of sulphobutylether beta cyclodextrin sodium, which is nephrotoxic through its reuptake from glomerular filtrate by the kidney tubules. This phenomenon has been shown for aminoglykoside antibiotics, which share this mechanism of toxicity. However, accumulation of drug delivery vehicles bare many potential risks to these critically ill patients and should be prevented $[10,11]$. Alternative antifungals like liposomal amphotericin B or caspofungin should be considered or intravenous voriconazole therapy should be switched to oral administration as soon as possible. The possible accumulation of sulphobutylether beta cyclodextrin sodium in patients under renal replacement therapy should be studied in prospective clinical studies in more detail. Furthermore, different renal replacement techniques like dialysis with high-flux membranes or continuous veno-venous hemofiltration need to be evaluated regarding the clearance of sulphobutylether beta cyclodextrin sodium.

\section{Voriconazole findings}

Regarding the voriconazole plasma levels published data in patients with renal insufficiency is rare. A case report in a patient with chronic renal insufficiency treated by continuous veno-venous hemodiafiltration, which focussed solely on voriconazole levels, demonstrated that no dosage adjustment was required [12]. The voriconazole plasma levels presently found in patients no. 1, 2, and 4 were in line with published data on healthy subjects 


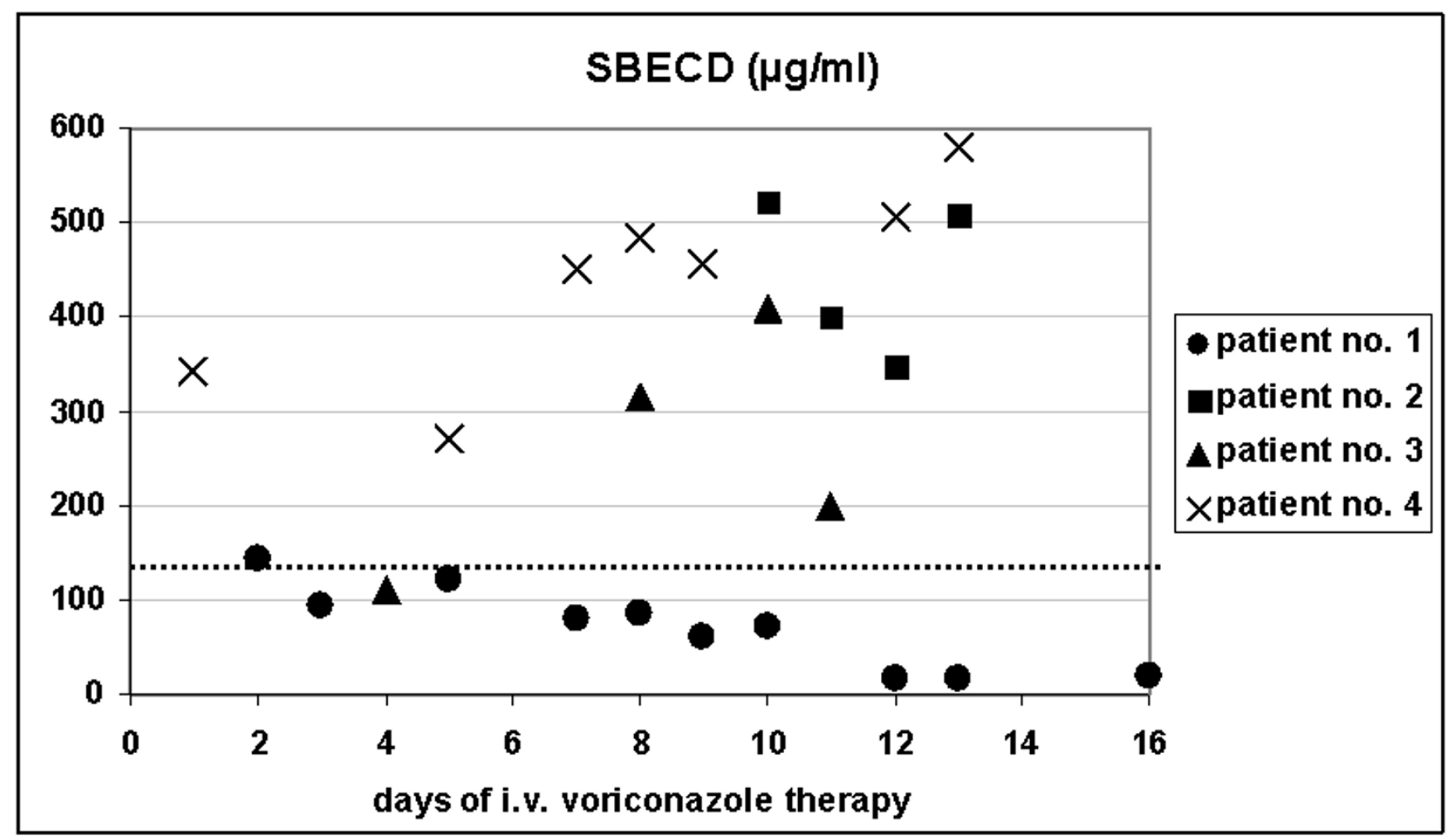

Figure I

Sulphobutylether beta cyclodextrin sodium (SBECD) levels in patients on intermittent dialysis receiving intravenous voriconazole. Patients no. $2-4$ with acute renal failure without recovery of renal function under intermittent dialysis receiving intravenous voriconazole show higher levels of sulphobutylether beta cyclodextrin sodium (SBECD) as compared to patient no. I with recovery of renal function. For comparison, in healthy volunteers peak SBECD levels of I30 $\mu \mathrm{g} / \mathrm{ml}$ (dotted line) were measured immediately following administration of $1600 \mathrm{mg}$ SBECD as a single infusion [9].

which received $3 \mathrm{mg} \mathrm{kg}-1$ twice daily. By day 12 this previous study showed a maximal concentration of voriconazole of $2.4 \mu \mathrm{g} / \mathrm{ml}$ and a half-life of 6.4 hours [13]. The trough levels of voriconazole presently determined were at several points lower than the minimum inhibitory concentrations for aspergillus spp., candida spp., and for most emerging fungal pathogens (minimal concentration $>0.8 \mu \mathrm{g} / \mathrm{ml}$ ). Nevertheless, voriconazole treatment levels $<0.2 \mu \mathrm{g} / \mathrm{ml}$ have frequently been observed in successfully treated patients and the manufacturer does not suggest a dosage adjustment [7]. The higher levels of voriconazole in patient no. 3 were in line with our previous observations that patients with liver insufficiency frequently show levels around $5 \mu \mathrm{g} / \mathrm{ml}$ (our valid range for voriconazole plasma levels is from 0.2 to $10 \mu \mathrm{g} / \mathrm{ml}$ ). Previous studies showed that liver function test abnormalities were statistically significant but weakly associated with elevated plasma voriconazole concentrations. To investigate potential threshold effects, patients with plasma voriconazole concentrations above and below various threshold values $(1,2,3,4,5,6 \mu \mathrm{g} / \mathrm{ml})$ were analyzed. These investigations did not identify threshold plasma concentra- tions above which the risk of a liver function test abnormality was higher compared with plasma concentrations below the threshold [4].

\section{Conclusion}

The present data indicated an accumulation of sulphobutylether beta cyclodextrin sodium in patients treated with intravenous voriconazole and dialysis therapy. Obvious adverse effects related to the accumulation of the drug delivery vehicle could not be observed, although the presently extrapolated dose values were lower but comparable with those used in animal experiments for toxicity studies. Intravenous application of voriconazole in patients on dialysis therapy should be evaluated carefully. Systematic clinical investigations are required to prevent potential harm to these critically ill patients due to an accumulation of sulphobutylether beta cyclodextrin sodium.

\section{Competing interests}

MAvM received speaking fees of 500 Euro from the manufacturer of voriconazole (Pfizer Pharma GmbH, Karl- 
sruhe, Germany). JB and LSW have no financial or nonfinancial competing interest related to the content of the manuscript.

\section{Authors' contributions}

MAvM treated the patients at the intensive care unit, conceived the investigation, collected the blood samples and drafted the manuscript. JB carried out the voriconazole and sulphobutylether beta cyclodextrin sodium analyses and helped to draft the manuscript. LSW treated the patients at the intensive care unit and participated in the coordination of the investigation. All authors read and approved the final manuscript.

\section{Acknowledgements}

This investigation was supported, in part, by Pfizer Pharma GmbH, Karlsruhe, Germany.

\section{References}

I. Herbrecht R, Denning DW, Patterson TF, Bennett JE, Greene RE, Oestmann JW, Kern WV, Marr KA, Ribaud P, Lortholary O, Sylvester R, Rubin RH, Wingard JR, Stark P, Durand C, Caillot D, Thiel E, Chandrasekar PH, Hodges MR, Schlamm HT, Troke PF, de Pauw B, Invasive Fungal Infections Group of the European Organisation for Research andTreatment of Cancer and the Global Aspergillus Study Group: Voriconazole versus amphotericin B for primary therapy of invasive aspergillosis. N Engl J Med 2002, 347:408-4I5.

2. Kullberg BJ, Sobel JD, Ruhnke M, Pappas PG, Viscoli C, Rex JH, Cleary JD, Rubinstein E, Church LW, Brown JM, Schlamm HT, Oborska IT, Hilton F, Hodges MR: Voriconazole versus a regimen of amphotericin B followed by fluconazole for candidaemia in nonneutropenic patients: a randomised non-inferiority trial. Lancet 2005, 366: 1435-I442.

3. Walsh T], Viviani MA, Arathoon E, Chiou C, Ghannoum M, Groll AH, Odds FC: New targets and delivery systems for antifungal therapy. Med Mycol 2000, 38(Suppl I):335-347.

4. FDA Antiviral Drugs Advisory Committee - Briefing Document for Voriconazole (Oral and Intravenous Formulations) [http://www.fda.gov/ohrms/dockets/ac/0l/briefing/ 3792b2 0l Pfizer.pdf]

5. Background Document for the Antiviral Drug Products Advisory Committee Meeting [http://www.fda.gov/ohrms/dock ets/ac/01/briefing/3792b2 02 FDA-voriconazole.htm]

6. Muhl E: Antimycotic drugs under continuous renal replacement therapy. Mycoses 2005, 48:56-60.

7. Prescribing information VFend ${ }^{\odot}$ [http://www.pfizer.com/pfizer/ download/uspi vfend.pdf]

8. Gage R, Venn RF, Bayliss MAJ, Edgington AM, Roffey SJ, Sorrell B: Fluorescence determination of sulphobutylether-b-cyclodextrin in human plasma by size exclusion chromatography with inclusion complex formation. J Pharm Biomed Anal 2000, 22:773-780.

9. Pennick GJ, Clark M, Sutton DA, Rinaldi MG: Development and validation of a high-performance liquid chromatography assay for voriconazole. Antimicrob Agents Chemother 2003, 47:2348-2350.

10. Kappe R: Antifungal activity of the new azole UK-109 496 (voriconazole): addition and clarification. Mycoses 200I, 44:432.

II. Hope WW, Denning DW: Optimising antifungal therapy for individual patients. Intern Med / 2004, 34: I47-I 49.

12. Robatel C, Rusca M, Padoin C, Marchetti O, Liaudet L, Buclin T: Disposition of voriconazole during continuous veno-venous haemodiafiltration (CVVHDF) in a single patient. J Antimicrob Chemother 2004, 54:269-270.

13. Purkins L, Wood N, Greenhalgh K, Allen MJ, Oliver SD: Voriconazole, a novel wide-spectrum triazole: oral pharmacokinetics and safety. BrJ Clin Pharmacol 2003, 56(Suppl I): I0-16.

\section{Pre-publication history}

The pre-publication history for this paper can be accessed here:

http://www.biomedcentral.com/1472-6904/6/6/prepub
Publish with Bio Med Central and every scientist can read your work free of charge

"BioMed Central will be the most significant development for disseminating the results of biomedical research in our lifetime. "

Sir Paul Nurse, Cancer Research UK

Your research papers will be:

- available free of charge to the entire biomedical community

- peer reviewed and published immediately upon acceptance

- cited in PubMed and archived on PubMed Central

- yours - you keep the copyright
BioMedcentral 